\title{
10 Black African Women in Engineering Higher Education in South Africa
}

\author{
Contending with History, Race, \\ and Gender
}

Yeukai Angela Mlambo

Globally, women and Black African ${ }^{1}$ women, in particular, are underrepresented in engineering professions. South Africa is not an exception. According to the Engineering Council of South Africa (2019), women represent less than 7\% of total registered professional engineers to date and about $24 \%$ of candidate engineers in training. In terms of race, Black Africans represent close to $20 \%$ of professional, registered engineers, while their white ${ }^{2}$ counterparts represent $74 \%$ (ECSA, 2019). Although women's presence is increasing in some engineering work spaces, including industry and government, they remain underrepresented in engineering academic careers in particular. Austin \& McDaniels (2006) state that a primary function of higher education is "to prepare the next generation of university faculty members" (p. 397). But what happens when university spaces are hostile towards Black women's bodies and identities? (Mabokela, 2001). Hurtado (1992) states that higher education environments are a product of history and context, institutional structures, group relations and ideologies. In essence, these historical backgrounds influence and impact how university campuses operate and how individuals engaging with and within those institutions experience the space(s).

In South Africa, higher education institutions continue to work their way out of their sullied apartheid pasts where Black women were excluded from full participation. Despite attempts at transforming institutional spaces and academic staff ${ }^{3}$ so that they reflect the diverse student population now attending these institutions, change remains slow. For example, across all institutions in 2018, Black academic staff as a combined aggregate of all non-white, permanent staff (i.e. African, Coloured, Indian or Asian) represented only 39.6\% of academic staff at public universities. In contrast, white people remained the largest population proportion of academic staff at $42.7 \%$ (Department of Higher Education \& Training, 2020). This in a country where white people make up less than $9 \%$ of the almost 59 million strong population.

Instead, in South African higher education Black Africans are over represented in support roles where they occupy about 97\% of administrative and service positions (Mabokela \& Mlambo, 2017). Where Black or Black Africans

DOI: $10.4324 / 9781003053217-1$ 
and women hold academic staff positions, they make up the majority of those below the $\mathrm{PhD}$ qualification, mostly employed as lectures or junior lectures (Mabokela \& Mlambo, 2017). In 2012, among Black Africans more narrowly, Black African women represented only 34 of the total 193 Black African professors at all public institutions (Price, 2014). By 2014, Black Africans represented only $4 \%$ of professors overall in South Africa, with Black African women in particular representing only $0.85 \%$ of the professoriate (Mlambo, 2017). In 2017, Black African representation among the South African public institution professoriate increased to $19.9 \%$, but Black African women in particular only represented $4.2 \%$ of South African professors overall (Higher Education Data Analyzer, 2020). In terms of engineering programs specifically, across all public institutions Black African women are glaringly absent. Where present, Black African women occupy junior roles and are often the only Black African individual among the academic staff in a department or college ${ }^{4}$ (Mlambo \& Mabokela, 2017).

When discussing the history of women's education in South Africa, Megan Healy-Clancy (2013) states that "consumed by the overarching racialized indignities of apartheid education, scholars have neglected how it was also a gendered project" (p. 121). I argue that for Black women in South Africa, race and gender play significant roles in not only their educational experiences, but ultimately in the career pathways Black women are able to pursue. Furthermore, race and gender are experienced as connected to a history that continues to devalue, exclude, and alienate Black Africans from academia even today. In an attempt to understand Black African women's absence in South African engineering academia, I focus my attention on understanding more broadly the factors that influence Black African South African women engineers' career choices, taking into consideration their higher education experiences.

In the next sections I provide background for understanding the racist and sexist history of higher education and engineering education in South Africa. Thereafter, using evidence from qualitative interviews conducted with 18 Black African women engineers who attended historically white institutions in South Africa, I highlight how race and gender continue to be significant factors impacting the higher education experiences of Black African women engineers I find that Black African women's experiences in higher education influence their career choices after graduation, directing them away from academia.

South Africa provides a unique socio-political context for understanding the ways in which the intersections of race and gender affect Black women's experiences in higher education more broadly, and in engineering higher education more specifically. To understand Black African women engineers' career decision-making and career outcomes as they relate to academia, one has to first understand the histories of higher education and engineering education in South Africa. Any effort to increase the percentage of Black African women who study engineering in South Africa must address the lack of Black African women who can act as teachers and mentors to future generations of undergraduate students. 


\section{Background to Higher Education and Engineering in South Africa}

The national elections in 1994 marked the end of the formal apartheid era, the transition to a new democratic South African government, and the introduction of new policies aimed at redressing the racial discrimination of apartheid higher education (Thomas, 1996). Prior to 1994, higher education access was segregated by race and ethnicity such that Black people were not permitted to attend or take on employment at designated white-only institutions (Reddy, 2004). Worth noting, engineering degrees were offered exclusively at these white-only institutions, which Black people could not easily access. Enrollment numbers at the time show how Black people had generally limited access to higher education overall. For example, in 1993, a year before the first democratic elections in South Africa, Black students represented only $6.3 \%$ of higher education enrollments. In the sciences, white students filled 67 enrollment positions for every one Black student, while in engineering the ratio was even wider as Black students represented one out of every 148 white students (Watson et al., 1997).

The discriminatory and segregated practices were rooted in the legislation of the Bantu Education Act, also known as the Black Education Act of 1953 as well as the Extension of University Education Act of 1959. Both legislative acts enforced racial segregation of educational facilities. The Bantu Education Act determined a specific and limited educational curriculum for Black Africans, rooted in the belief that "black people should be subjugated through education to enforce apartheid ideology" (Ndimande, 2013, p. 22). At its core, Bantu Education was intended to socialize Black people to accept the social norms of apartheid, by enacting educational frameworks that emphasized white superiority and Black inferiority. At the higher education level, the Extension of University Education Act expanded segregation to include higher education institutions, criminalizing any Black people that attended newly designated white institutions without written permission from the Minister of Internal Affairs. Alternate higher education institutions were created and designated for different racial and ethnic groups, with restrictions on who could attend based on their race or ethnic identity. Although the Extension of University Education Act was repealed in 1988, the irreparable damage such policies caused continue to plague the nation today (Akoojee \& Nkomo, 2007). Questions of belonging, though no longer explicitly stated, remain part of the unspoken foundation of South African higher education, albeit now couched in conversations about how to maintain quality as higher education institutions increase access (Akoojee \& Nkomo, 2007).

\section{Post-Apartheid Higher Education}

Post-apartheid policies, including the Education White Paper 3 (Department of Education, 1997) and the National Plan for Higher Education, called out 
racial inequalities in access and provided policy directives to "promote equity of access and redress past inequalities" (Ministry of Education, 2001, p. 12). In particular, Education White Paper 3 noted how problematic it was that despite institutions opening their admissions to students from all races, higher education staff at these institutions, primarily the historically white institutions (HWIs), remained overwhelmingly white (Mlambo, 2017). The White Paper stated, "unlike the changing student profile, especially in undergraduate programs, the composition of staff in higher education fails to reflect demographic realities ... Black people and women are severely underrepresented, especially in senior academic and management positions" (Department of Education, 1997, Section 2.94). While some progress has been made in terms of diversifying student representation, most higher education institutions "have retained as a majority the race group the university historically served" (Mlambo, 2017, p. 9).

Unfortunately, over 25 years after the end of apartheid, Black women continue to experience higher education as racialized and gendered spaces, which hinders Black women's meaningful participation as students, staff and faculty (Mabokela \& Mawila, 2004; Mabokela \& Mlambo, 2017; Mlambo, 2017). In addition to building names and plaques on campus being subtle reminders of the racist legacy, in some cases campus environments are blatantly harmful to Black bodies. Reports of incidents where Black bodies are dehumanized by white students create undue stress for Black students. For example, in 2008 four white students at the University of Free State made three Black women university cleaning staff drink urine and filmed the incident, which they had staged in protest of the university's decision to racially integrate the residence halls that until then had been divided by race (Norgaard, 2008). In a 2019 report, the Institutional Reconciliation and Transformation Commission (IRTG) of the University of Cape Town found that racism is rife at the University of Cape Town, a prestigious, world-ranked institution, which in 2015-2016 was the center of student protests against institutional racism with demands for decolonization of African higher education, including the removal of artifacts of colonization such as the Cecil John Rhodes statue. These are the higher education learning environments that Black students engage with on a daily basis in South Africa.

Today, the South African postsecondary school education and training system is made up of 26 public traditional and comprehensive universities and numerous other private institutions and technical colleges (DHET, 2020). In 2018, these public universities enrolled 1,085,568 students, a significant increase in access from the 495,356 enrolled in 1994. The highest enrollments were in science, engineering and technology (SET) programs, which accounted for $29.5 \%$ of enrolled students, followed by business $(26.1 \%)$, humanities and social sciences $(24.6 \%)$, and education (19.7\%). In the same year, SET programs registered 65,000 students who graduated from these programs, the highest number of graduates compared to other disciplines. 
In terms of enrollment, women's gross enrollment ratio surpasses men's enrollment by $40 \%$ overall and Black Africans occupy a $75.6 \%$ share of enrollment. While women represent the majority of students across all disciplines, they occupy a slight minority in SET (46.7\%). Despite Black African students representing a majority of the student population, academic staff remain predominantly white, and Black students in engineering are especially likely to complete their undergraduate and graduate education without being taught by a Black professor and definitely not by a Black female professor (Mlambo, 2017).

\section{Black Women's Post-Apartheid Higher Education Experiences}

Shortly after transitioning to democracy, a 1996 South African higher education report concluded that "the experiences by female and Black students and staff in particular suggest that conditions at institutions often do not facilitate the full participation of members of all social categories and groups" (National Commission on Higher Education, 1996, p. 39). The 1996 report pointed to the need for radical transformation of the policies and practices at institutions around the country for South Africa to move away from the racist and sexist norms of the apartheid era. However, by 2012, a quantitative study examining the relationship between student engagement and sense of belonging among South African higher education students highlighted how race remains a salient factor in the educational lives of Black African South African students (Wawrzynski, Heck \& Remley, 2012). Today, higher education institutions in South Africa are a constant reminder of an apartheid era that may have ended politically, but whose institutions, buildings, policies, and bodies continue to reflect and represent that dark legacy. This residual racism is also felt in the classroom, and is acted out by both lecturers and students (Wawrzynski et al., 2012; Cross et al., 2009).

African scholar Amina Mama (2003) argues that, “the 'African' universities established after independence did not mark a radical departure from the colonial modes of organizational and intellectual life" (p. 106), which she describes as "male preserves, dedicated to the production of good colonial subjects" (p. 105). In her analysis of the impact of gender on higher education in Africa, Mama (2003) goes on to explain how despite claims by African universities that they operate as neutral entities, "the institutional and intellectual cultures of African institutions are, in fact, permeated with sexual and gender dynamics" (Mama, 2003, p. 101). Furthermore, hostile higher education environments for women "operate in ways that are very likely to jeopardize women's academic career prospects" (p. 118).

In South Africa, Mama's insights can be observed in the composition of faculty and staff across the country. The experiences of Black women engineers are perhaps to be expected, given the history of the discipline as its purpose aligned with the higher education mandate during colonial times. The purpose of engineering in Africa was to advance the mission of the colonies. In doing so, engineering policies and the higher education spaces that trained engineers 
determined who could participate and in what ways (Muller, 2018). As noted previously, until 1994 with the transition to democratic rule, Black Africans were treated as second class citizens in South Africa. Various laws forbid full or any participation of Black South Africans from a majority of higher education and employment spaces. White men could enroll in engineering courses, but Black people had to apply for special permission to attend white institutions, which were the only places offering engineering credentials (Cruise, 2011). Some sectors such as mining were subject to legislation that prohibited hiring women engineers. In addition, non-whites were not allowed to become certified miners effectively securing the senior mining positions for white people only and deterring Black women from pursuing mining engineering in particular (Cruise, 2011).

After 1994, as engineering companies began to more actively recruit and accept Black South Africans, more young Black people were encouraged to pursue engineering. National affirmative action policies were put in place to incentivize organizations that hired Black people and women. Companies began to provide higher education bursaries and sponsorship to recruit Black women into engineering, creating their own pipeline of future employees who would be contractually obligated to work for the company upon graduation, in exchange for a full scholarship (Republic of South Africa, 1998). Participation in engineering then became a pathway for social mobility for the individual and her family (Mlambo, 2017).

As Black people mostly came from low socio-economic backgrounds due to historical disenfranchisement, the ability to attend higher education with sponsorship and to subsequently secure a well-paying job upon graduation was appealing (Firfirey \& Caolissen, 2010). Black women were drawn to engineering, because it "was the embodiment of an apartheid system of exclusion that they were interested in infiltrating and establishing a legacy as one of the first Black women in the field" (Mlambo, 2017, p. 194). In contrast, academia was viewed as low paying in comparison to industry and had negative associations with the teaching profession (Mlambo, 2017). Given the restrictions on employment options during apartheid where Black women's career options were limited to teaching and nursing, "teaching was less prestigious and not appealing for these women" (Mlambo, 2017, p. 195). As industry spaces deliberately targeted women and Black women in particular, Black women were increasingly drawn towards careers in industry and away from academia.

Despite Black people having legal access to attend higher education institutions of their choice and no longer being restricted by their race, institutional environments and policies continue to reinforce the idea that Black people are unwelcome in these spaces, especially HWIs. In a study to understand the career choices of Black African women engineers in South Africa, I conducted 18 interviews with Black women engineers, all with postgraduate ${ }^{5}$ engineering degrees who found employment in industry, government, or academia. The women had attended undergraduate engineering programs both before and after 1994, with most participants having been undergraduate students after 
1994. The women ranged in age from 24 to $50+$, with an average age of 32 years. Participants represented various engineering programs, with civil and metallurgical engineering most represented. The purpose of the study was to understand their career choices and to explain why for most of the women, academia was not a first career choice. For this chapter, I focus on the findings related to the racialized and gendered undergraduate higher education experiences the women described as factors influencing their career choices.

\section{Campus Climate, Black Experiences, Perceptions about Academia and Career Choice}

In reflecting on their higher education experiences, participants described their undergraduate experiences as taking place in white normative spaces, absent of mentorship for Black students, unwelcoming, and representative of an apartheid past where Black people were restricted from full and equal participation. I discuss some of their reflections and provide direct quotes as evidence to support their narratives.

\section{Whiteness as the Norm}

Participants described their higher education experience as a space where whiteness was the norm. The women shared how in their entire higher education experience in engineering, they had never been taught by a Black lecturer or professor. One participant recalls,

... we didn't have Black females or even Black lecturers to look up to at the time ... you know, the whole industry was white, it still is today. But back then it was more so, you know, so it's, it was difficult to even find, there were a few Black people and all male at the time ... (Lulama)

Another participant shared how white students often outnumbered Black students in their courses. Unfortunately, in order to survive their undergraduate sojourn, Black students had come to accept as status quo that whiteness was normative,

... Like we had accepted it. It's a matter of just saying we need to get our degrees and go, that's it. Yeah, we had accepted it ... it's just how it is, you can't change it, you are here so you just have to live with it. (Rose)

Once over the culture shock, participants quickly became accustomed to the racial imbalances in the classroom that favored white students. The prevalence of whiteness in engineering higher education reinforced the message that higher education was a white space, and, similar to apartheid times, Black bodies could be granted temporary access to gain their degrees with an understanding that they would move on to industry for their careers, and not remain in academia. 


\section{Limited Mentorship for Black Students}

A consequence of whiteness being the norm in engineering higher education was the lack of Black mentors available for Black students. For Black women, the absence of women role models can deter them from pursuing degrees and careers in SET. In terms of academic careers specifically, faculty are essential agents for socializing students into the culture of the discipline (Schuurman, Pangborn, \& McClintic, 2005). In reflecting on the absence of Black women mentors during their undergraduate studies, one participant shared,

I think I missed out. I think if there was someone like me, a Black woman, teaching me to become an engineer, I think that would've been that motherly touch to it as well. Someone you can go and speak to and ask questions. Someone who would inspire you. It would be more comfortable for you. I think I would have had a different perspective about engineering. (Mpho)

In addition to faculty not representing the diversity of the student population, participants reported how white professors would focus their recruitment, mentorship, and grooming efforts on white students and rarely, if ever, on Black students in their classrooms. One participant shared that no matter how good a Black student was, and even when peers would embrace them despite their racial differences, white lecturers were less open to engaging with Black students in the same way they did with white students. The limited engagement of white lecturers with Black students also meant that Black students were less likely to know about the career aspects of academia. "I think its just a lack of knowledge, information. Because I don't even know what qualifies one to be a professor, a lecturer. I don't know" (Teboho). Essentially, "Black people were not made aware of the rules of academia," thereby diminishing their potential to develop an informed interest in higher education as a career space (Mlambo, 2017, p. 209).

Additionally, Black women perceived that white lecturers pre-determined which white students they wanted to mentor into academic careers, therefore Black students, no matter how good, often did not stand a chance.

The lecturers decide who they want as lecturers by the time we graduate ... so if I come there and I'm like you know what I would love to teach this, but this guy has been groomed already for this position ... how are you gonna come in an destabilize that foundation? (Tumelo)

The absence of encouragement these women felt from their higher education lecturers was in sharp contrast to their pre-tertiary educational experiences, where teachers of all races were notably encouraging of these same Black women to pursue engineering. One participant shared that 
my teachers at school, you know when you're in high school ... they're the ones who shape your career choice, they tell you 'oh my gosh you're so good in maths you're so good in science you should consider engineering' (Melita). This encouragement and mentorship propelled them into engineering but was not sustained by their new instructors at the undergraduate level, who instead appeared to hold a deficit perspective of Black women's talents in engineering academia in particular. "The history of apartheid and the racial hierarchies and prejudices the apartheid system created which presented Black people as incapable scholars remained present among older academic staff in engineering higher education. (Mlambo, 2017, p. 126)

These feelings of racism and alienation dissuaded Black women from considering academic careers for themselves.

South African authors Cross, Shalem, Backhouse \& Adam (2009) reported similar findings where Black students from an HWI felt they were "undermined from an academic perspective and deliberately prevented from succeeding" in engineering and the humanities as "white students are offered academic support that is not offered to black students" (p. 32). As a result, the students experienced the institution as an unwelcoming space that favored white students and where Black students would never be viewed as capable students. Mangcu (2014) states that standards of academic potential in South African universities continue to be measured by whiteness. As young Black women do not see themselves in the faces of those occupying career positions in academia, there are effectively no opportunities to imagine oneself as performing that role.

In contrast, Black women undergraduate students increasingly found representations of themselves as well as willing mentors in industry spaces through the various internships Black women participated in during their school holiday breaks.

While now we were, I was in tertiary, coming for vacation work, I would see one Black engineer, young. You know, he just qualified. He's starting now as a manager. That will ignite the passion even more ... so those are the people that kept me going [they would say to me] - "Wow, we hear about you, we can see you're hard working. Keep going. You can do this. (Noku)

These experiential learning opportunities became the gateways to building understanding about what it means to be a Black African engineer in industry and reinforced the message that women, and Black African women specifically, were welcome in industry.

\section{Higher Education as Unwelcoming}

As industry welcomed Black African women with some enthusiasim, higher education continued to provide unwelcoming experiences for Black women. 
In my study, the absence of Black African women amongst engineering lecturers or professors added to feelings among Black African women students that academia was not meant for people who looked like them, and "that perhaps the academy itself did not want them" (Mlambo, 2017, p. 208). One woman shared,

And I suppose the environment as well. It's just not that attractive. It's still like an old boys club, if I can put it like that. So it's yeah, and it's like that wherever you go, whether it's (university 1, 2 or 3) it's still like that. It's still a club of closed circle of people who speak a particular language and you can go be the brave one and go in but then you risk being the token in the group. (Audrey)

Black African women also used white women as a benchmark to further determine whether or not Black women belonged in academic careers. One participant noted her reservations at trying to enter higher education career spaces where white women were also struggling to succeed. "Even the white women lecturers find it tough to compete in that male environment, and they are white!" (Tumelo). As a result, Black African women viewed their time in higher education as a temporary life event which would inevitably end upon conferral of their degrees, allowing them to move on to careers in industry. "... I think usually when we think of engineering, we tend to more think of not academia. Yeah, I think when you're thinking academics, you think I must go through it and go work somewhere else" (Vuyo). The Black African women in my study "had reconciled early in their higher education process that engineering academe was a white space Black people had to survive" (Mlambo, 2017, p. 197) and promptly leave for something else outside of the university space.

In addition to the negative experiences with faculty, their undergraduate experiences solidified for Black women that they would not want to pursue careers in academe.

The one decision that I made when I was a student, I said I'm not gonna be a lecturer. You need to know your stuff. Kids can be mean sometimes. They'll ask you certain things just to expose you. That's how students are. I said ok, you need to know your stuff when you become a lecturer so I am not gonna be lecturing anytime soon. (Teboho)

In the absence of mentors and already feeling alienated from the academy, Black women seldom sought out information that could challenge their (mis)perceptions. As a result, "An academic career, which would inevitably involve spending more time in a predominantly white space, was not even considered" (Mlambo, 2017, p. 125), or in the case of Teboho, was outright rejected based on the information she had at her immediate disposal. 


\section{Freeing Themselves and Their Families from Apartheid}

The less than positive higher education experiences Black women encountered are linked to the historical legacy of apartheid and the socio-economic positioning of Black African women over time in South Africa. In addition to navigating a hostile higher education environment, the Black African women were also actively working to free themselves and their families of the legacy of apartheid.

Black African women viewed higher education as an extension of their pretertiary schooling. Thus, they saw higher education lecturers as equivalent to their primary and high school teachers, integral in getting them to move on to their next educational phase, but not as career role models whom they themselves might wish to become one day. As higher education lecturers were equated with school level teachers, and given the legacy of apartheid that limited Black women to teaching roles, the Black women in my study who were eager to shake off the legacy of apartheid did not see teaching as a prestigious occupation in the current political dispensation. Instead, they believed it was their family and community duty to transcend the career designations imposed on Black women during apartheid by occupying spaces in the engineering industry where they were previously banned.

As first-generation engineers in their families, these Black African women were motivated to use their education to elevate their families and communities into previously unachievable socio-economic levels. Academia as a career was not perceived as providing the necessary social and economic resources to achieve that goal at the same rapid pace that industry careers could. A Dean of an engineering school in South Africa confirmed that academia does not have the same rewards that industry does in financial terms. For Black people who come from impoverished backgrounds, academia then becomes less appealing than industry. One Black African woman participant reiterated this notion of generational responsibility and why Black African women pursue engineering but do not consider academic careers in the process,

... as a Black woman, you want to go back home and do things for your home and that's why as soon as you get in a position to study, you want to go and do something that can bring finances to go and support your family. Because we feel a lot of responsibility. Especially in our generation, we felt that, okay, we were one of the first, you know, the first groups to get bursaries and get proper education ... as soon as you get that opportunity, you want to do it so that you can actually provide for your sisters, your mothers, your grandmothers because there is a lot of responsibility that you naturally just carry. (Mpho)

Black women's identities within their families and communities, coupled with their motivations to transcend pre-1994 policy restrictions, as well as the strong messaging of unbelonging they received from higher education spaces, influenced their career considerations away from academia. 


\section{Discussion}

This chapter explored how race and gender, within historical national contexts, influences the career considerations and choices of Black women engineers in South Africa away from academic careers and towards careers in industry. Despite representing the majority of the population, Black African women in South Africa remain noticeably underrepresented in engineering academia. As South African universities focus on redressing the inequities of apartheid by increasing access for Black students, faculty composition remains notably white and male, especially in engineering programs.

For Black African women engineers in South Africa, career pathways represent a journey of negotiating with social, cultural, economic, and historical barriers and incentives that guide Black women towards some careers and deter them from others. In this chapter, I argued that undergraduate higher education experiences influence postgraduation career outcomes for students. For Black African women in engineering, their higher education experience is often a process of surviving in predominantly white, male, and hostile spaces - both within their programs specifically and at the institution more broadly (Mlambo, 2017). These early higher education experiences remind them of who belongs and who does not belong in higher education spaces. These early messages not only impact their immediate educational experiences, but have a lasting impact on the perception of academia as places of work.

Almost 25 years after transitioning to democracy, Black African undergraduate engineering students continue to experience higher education as a racialized and gendered space. Given the glaring history of South African higher education, as well as the history of engineering in the country, it is not surprising that Black African women continue to feel like they do not belong in the academy.

Therefore, institutions should care about what environment they are creating as well as what educational experiences they are providing as these are linked to their institutional mandates to recruit, educate, and graduate students (Gayles \& Ampaw, 2011, p. 20). More often than not, teaching and learning spaces are racialized and gendered in ways that are unwelcoming to Black bodies in particular (Mlambo, 2017; Porter et al., 2018). As a result, the absence of Black women in engineering academia is a reflection of higher education spaces that still have not invited Black women as true participants in the modern African higher education project or in engineering education (Mlambo \& Mabokela, 2017). Hurtado (1992) states that "institutions that increase their commitment to diversity can significantly improve their social environments for minorities" (p. 21). Before even thinking about the transformation needed in the academic workplace for faculty and staff; to attract and retain Black African women and other minoritized identities, the learning environments in which they pass through while they are students need to embody inclusivity for Black women to even consider these spaces as possible places to pursue employment. 
In the absence of faculty who look like them, with no role models and no one providing additional information or trying to actively recruit these women for academe, Black African women come to experience higher education only as a transitory space, a necessary stepping stone on their way to other careers outside of academia (Mlambo, 2017). Failure to change higher education learning environments for Black women will hinder the ability to recruit and retain Black women in the academy and in engineering programs in particular.

\section{Implications}

The findings of this study have implications for policy and practice. At the policy level, the findings indicate that department and program faculty and staff are in a position to more directly influence the career considerations of students. Black African women lamented that they have little to no information about what an academic career entails. Access to information through student-facing faculty seminars, increasing undergraduate research programs, and providing similar vacation work opportunities to what industry offers will allow for more Black African women to understand what an academic career entails and to explore their potential place in the system.

Furthermore, institutions can allocate resources to support engineering departments to engage in more immediate and high-touch recruitment and grooming efforts to encourage more Black African women to consider academia as a career. Provision of more scholarship programs or tuition waivers for previously disadvantaged populations will allow for departments to build their own pool of future faculty, in the same way that industry streamlines the careers of recipients of their funding packages. As many Black African women are interested in pursuing postgraduate credentials, higher education institutions are at an advantage for recruitment if they can create pathways to academic careers by providing funding support and research opportunities for postgraduation education for Black students. In competition with industry, schools of engineering will fail to adequately recruit future faculty if they do not put forward significant resources to do so.

Race and gender remain salient factors influencing the higher education experiences of Black African women in engineering. The culture of whiteness as normative needs to be dismantled and replaced with a more inclusive culture that celebrates Black bodies and their intellectual contributions to science and engineering. In addition to physical representation, individuals want to see their ideas and their knowledge valued in the spaces where they are present. As faculty composition may be slow to diversify, the higher education environment needs to be welcoming to non-white students and Black African students should be able to recognize themselves in the curriculum, policies, and other symbols in the spaces where they engage, interact, and are educated. Culture change is not limited to representations among faculty, but encompasses other non-human messaging Black students receive as they survive higher education spaces. 


\section{Conclusion}

In my study, Black women engineering students reported an uneasy lack of confidence in their ability to teach others, even as they felt comfortable in their role practicing engineering in industry, government, or elsewhere. Ndimande (2013) reminds us that the purpose of education for Black people during the apartheid era was to subjugate, control, and stabilize the Black population to remain semi-skilled workers, subservient to their white counterparts. Furthermore, as Mama (2003) stated, higher education in Africa was meant to produce good workers to maintain the colonies. Black African women's discomfort with the academy is a result of decades of racialized and gendered messaging about belonging that has transcended generations. A failure to transform this damaging narrative about Black African women engineers' positioning in the knowledge enterprise will unlikely change the status quo, as Black African women will continue to opt out of academia.

\section{Notes}

1 In South Africa, Black is used to describe either all non-white individuals (including people of African, Coloured and Indian descent) or African people. For consistency with South African data reporting, in this chapter Black will be used to refer to all non-white peoples, while Black African will be used to describe individuals of African descent, distinct from Coloured, Indian and white South Africans. In South Africa, racial categories include Black African, Coloured, Indian/Asian, and white. Although the term Coloured is denigrating in some contexts, in South Africa this is an official racial category.

2 The use of the lowercase w for white or whiteness in this paper is the author's stylistic act of decentering whiteness in order to amplify Black women's experiences.

3 The word staff is used to refer to employees. South African higher education data refers to academic staff when identifying teaching and learning faculty employees.

4 College is used for ease of readership, but in South African colleges are referred to as faculties, (e.g. Faculty of Engineering) with departments used to delineate the different academic programs (e.g. Civil Engineering Department).

5 Postgraduate degrees in South Africa refer to any degree that is higher than a Bachelor's degree, e.g. honors, master's, or doctoral degrees.

\section{References}

Akoojee, S., \& Nkomo, M. (2007). Access and quality in South African higher education: The twin challenges of transformation. South African Fournal of Higher Education, 21(3), 385-399.

Austin, A. E., \& McDaniels, M. (2006). Preparing the professoriate of the future: Graduate student socialization for faculty roles. In J. C. Smart (Ed.), Higher education: Handbook of theory and research (Vol. 21, pp. 397-456). Springer. https://doi.org/10. 1007/1-4020-4512-3_8

Cross, M., Shalem, Y., Backhouse, J., \& Adam, F. (2009). How undergraduate students 'negotiate' academic performance within a diverse university environment. South African Fournal of Higher Education, 23(1), 21-42. 


\section{Teukai Angela Mlambo}

Cruise, J. A. (201 1). The gender and racial transformation of mining engineering in South Africa. The Journal of Southern African Institute of Mining and Metallurgy, 111, 217-224.

Department of Education. (1997). White paper for the transformation of higher education. http://www.che.ac.za/sites/default/files/publications/White_Paper3.pdf

Department of Higher Education and Training. (2020). Annual performance plan 2020/21. https://www.dhet.gov.za/SiteAssets/DHET\%20Annual\%20Performance $\% 20$ Plan $\%$ 202020.pdf

Engineering Council of South Africa. (2019). Annual report 2018/19. https://www.ecsa. co.za/news/Annual\%20Reports/2018-19\%20ECSA\%20Annual\%20Report.pdf

Firfirey, N., \& Carolissen, R. (2010). "I keep myself clean ... at least when you see me you don't know I am poor": Student experiences of poverty in South African higher education. South African Fournal of Higher Education, 24(6), 987-1002.

Gayles, J. G., \& Ampaw, F. (2011). Gender matters: An examination of differential effects of the college experience on degree attainment in STEM. New Directions for Institutional Research, 152, 19-25.

Healy-Clancy, M. (2013). A world of their own: A history of South African women's education. University of KwaZulu-Natal Press.

Higher Education Data Analyzer. (2020). Peer data reports. https://www.heda.co.za/ PowerHEDA/dashboard.aspx

Hurtado, S. (1992). The campus racial climate: Contexts of conflict. Institute for Higher Education Law and Governance Monograph, 90-97. https://www.law.uh.edu/ihelg/m onograph/90-7.pdf

Mabokela, R. O. (2001). Introduction: Soaring beyond boundaries. In R. O. Mabokela \& A. L. Green (Eds.), Sisters of the academy: Emergent Black women scholars in higher education (pp. xiii-2). Stylus Publishing LLC.

Mabokela, R. O., \& Mawila, K. F. N. (2004). The impact of race, gender, and culture in South African higher education. Comparative Education Review, 48(4), 396-416.

Mabokela, R. O., \& Mlambo, Y. A. (2017). Access and equity and South African higher education: A review of policies after 20 years of democracy. Comparative Education Review, 61(4), 780-803.

Mama, A. (2003). Restore, reform but do not transform: The gender politics of higher education in Africa. Fournal of Higher Education in Africa, 1(1), 101-125.

Mangcu, X. (2014, July). 10 steps to develop Black professors. City Press. https://www. uct.ac.za/usr/news/2014/10\%20steps\%20to\%20develop\%20black\%20profes sors.pdf

Ministry of Education. (2001). National plan for higher education. Pretoria, South Africa: Ministry of Education.

Mlambo, Y. A. (2011). Women in engineering academia: Reasons for commitment to the field [Master's thesis, University of Pretoria].

Mlambo, Y. A. (2017). Why not academia? The streamlined career choice process of Black African women engineers: A grounded theory study [Unpublished doctoral dissertation]. Michigan State University.

Mlambo, Y. A., \& Mabokela, R. O. (2017). 'It's more flexible': Persistence of women engineers in the academy. European Fournal of Engineering Education, 42(3), 271-285. https://doi.org/10.1080/03043797.2016.1158790

Muller, M. (2018). Decolonising engineering in South Africa-Experience to date and some emerging challenges. South African Fournal of Science, 114(5-6), 1-6. https://doi. org/10.17159/sajs.2018/a0270

National Commission on Higher Education (NCHE) (1996). A framework for transformation. Pretoria. 
Ndimande, B. S. (2013). From Bantu education to the fight for socially just education. Equity E Excellence in Education, 46(1), 20-35. https://doi.org/10.1080/10665684. 2013.750199

Norgaard, K. (2008, February 28). Whites tricked blacks into consuming urine, university says. CNNN. http://edition.cnn.com/2008/WORLD/africa/02/27/saf.racist.video/ index.html

Porter, C. J., Mlambo, Y., Hannibal, J., \& Karunaratne, N. (2018). (Re)defining student success: A qualitative study of Black undergraduate women pursuing veterinary medicine. Fournal of Women and Minorities in Science and Engineering, 24(1), 61-80.

Price, M. (2014). Staff transformation at UCT. University of Cape Town, Daily News. https:// www.news.uct.ac.za/article/-2014-07-14-staff-transformation-at-uct

Reddy, T. (2004). Higher education and social transformation South African case study. Council on Higher Education, Pretoria, South Africa. http://www.che.ac.za/sites/ default/files/publications/HEandSocialTransformationReport_25Feb2004.pdf

Republic of South Africa. (1998). Employment Equity Act No. 55, 1998. Cape Town, South Africa.

Schuurman, M. K., Pangborn, R. N., \& McClintic, R. D. (2005). The influence of workplace experience during college on early post graduation careers of undergraduate engineering students. Women in Engineering ProActive Network.

The Institutional Reconciliation and Transformation Commission. (2019, March). The final report. University of Cape Town. https://www.news.uct.ac.za/downloads/irtc/ IRTC_Final_Report_2019.pdf

Thomas, D. (1996). Education across generations in South Africa. The American Economic Review, 86(2), 330-334.

Wawrzynski, M. R., Heck, A. M., \& Remley, C. T. (2012). Student engagement in South African higher education. Fournal of College Student Development, 53(1), 106-123. https://doi/org/10.1353/csd.2012.0007 